\title{
Optical properties and photoconductivity of amorphous silicon carbon nitride thin film and its application for UV detection
}

\author{
C.W. Chen ${ }^{\mathrm{a}, *}$, C.C. Huang ${ }^{\mathrm{a}}$, Y.Y. Lin ${ }^{\mathrm{a}}$, L.C. Chen ${ }^{\mathrm{b}}$, K.H. Chen ${ }^{\mathrm{c}}$, W.F. Su ${ }^{\mathrm{a}}$ \\ ${ }^{a}$ Department of Materials Science and Engineering, National Taiwan University, 1, Roosevelt Road, Sec. 4, Taipei 106, Taiwan \\ ${ }^{\mathrm{b}}$ Center for Condensed Matter Sciences, National Taiwan University, Taipei, Taiwan \\ ${ }^{\mathrm{c}}$ Institute of Atomic and Molecular Sciences, Academic Sinica, Taipei, Taiwan
}

Available online 28 January 2005

\begin{abstract}
Optical properties of amorphous silicon carbon nitride thin films as a function of carbon content have been studied by the spectral microreflectometry. The compositions of a-SiCN thin films deposited with different $\mathrm{CH}_{4}$ flow rates were analyzed by $\mathrm{X}$-ray photoemission spectroscopy (XPS). It was found that the transmittance of a-SiCN thin films decreases with the increasing carbon content; the index of refraction $n$ varies from $\sim 2.0$ to $\sim 2.2$ and the optical gap (Tauc gap) $E_{\text {opt }}$ value progressively decreases from 4.1 to $3.3 \mathrm{eV}$ while the carbon content changes from 0 to $25 \%$ in the films. In addition, a MSM (metal-semiconductor-metal) photodetector device based on the a-SiCN thin film demonstrates excellent selective sensing features with a large photo-to-dark current ratio about 1800 under illumination of the $250 \mathrm{~nm}$ UV light source, providing potential applications for low-cost UV detection.
\end{abstract}

(C) 2004 Elsevier B.V. All rights reserved.

Keywords: Amorphous silicon carbon nitride; Optical band gap; MSM; UV detector

\section{Introduction}

Silicon carbide (Si-C) and silicon nitride $(\mathrm{Si}-\mathrm{N})$ have wide applications in mechanical, optical and electronic devices [1]. Carbon nitride, a highly promising hard material, has also received increasing attention recently [2]. More recently, a new class of ternary silicon carbon nitride $(\mathrm{SiCN})$ materials with large (several tens of microns) and well-facet crystals have been grown successfully by microwave plasma-enhanced chemical vapor deposition (MW-CVD) by Chen et al. $[3,4]$ and Badzian and Badzian [5]. These newly discovered SiCN crystals have been found to demonstrate a great potential for applications in semiconductor technology as well as a structural material. They show excellent mechanical properties with hardness and bulk modulus around 30 and $322 \mathrm{GPa}$, respectively. The optical investigation of polycrystalline $\mathrm{SiCN}$ films shows a

\footnotetext{
* Corresponding author. Tel.: +88623366 5202; fax: +886223634562.

E-mail address: chunwei@ntu.edu.tw (C.W. Chen).
}

direct band gap of about $3.8 \mathrm{eV}$ and a strong optical emission around $2.8 \mathrm{eV}$ [4]. The ternary $\mathrm{SiCN}$ compound constitutes an important wide band gap material with a gap energy within the blue-UV spectral region. It is believed that the chemical bonding and atomic local order can be quite complex in the ternary SiCN system. The atomic structure of $\mathrm{SiCN}$ crystals can be described as the pseudo $\alpha-\mathrm{Si}_{3} \mathrm{~N}_{4}$ phase, which shows some deviation from the pure $\alpha-\mathrm{Si}_{3} \mathrm{~N}_{4}$ pattern in the X-ray diffraction experiment. The similarity of local atomic structures between $\mathrm{SiCN}$ and $\alpha-\mathrm{Si}_{3} \mathrm{~N}_{4}$ is also evident from the experiment by the $\mathrm{X}$-ray-absorption spectroscopy [6]. Composition and bonding analyses strongly suggest the structure of $\mathrm{SiCN}$ to be a solid solution and $\mathrm{SiNx}$ and $\mathrm{CNx}$, in that $\mathrm{C}$ atoms substitute only for the $\mathrm{Si}$ sites and vice versa [7]. It is expected that carbon content plays an important role in determining physical properties of a-SiCN thin films. Indeed, it has been reported that the thermal diffusivity, density and hardness of a-SiCN thin films decreased with increasing carbon content [8]. In this article, we would like to present a systematical study on the optical and photoconductive properties of a-SiCN thin films 
as a function of carbon content and the potential applications for UV light detection.

\section{Experiment method}

Microwave plasma enhanced chemical vapor deposition (MW-CVD, AsTex, $5 \mathrm{~kW}$ ) systems were employed to grow the $\mathrm{SiCN}$ films on the $\mathrm{Si}(100)$ and fused silica substrates, respectively. Details of the MW-CVD systems have been described elsewhere [7]. In brief, a $1.5 \mathrm{~kW}$ microwave source was employed to generate plasma as a mixture of semiconductor grade $\mathrm{SiH}_{4}, \mathrm{NH}_{3}, \mathrm{CH}_{4}$ and $\mathrm{H}_{2}$ gases in various proportions was used to deposit a-SiCN thin films. By adjusting the flow rate ratio of different gases, films with various compositions were obtained. A microwave power of $1000 \mathrm{~W}$ was set and the chamber pressure was kept at about $3.73 \mathrm{kPa}$ during deposition. In order to systematically investigate the bonding configurations of a-SiCN films, we varied the $\mathrm{CH}_{4}$ flow rate from 0 to $30 \mathrm{sccm}$ and kept the flow rates of $\mathrm{SiH}_{4} 3 \mathrm{sccm}, \mathrm{NH}_{3} 30 \mathrm{sccm}$ and $\mathrm{H}_{2} 100 \mathrm{sccm}$ unchanged during deposition. Incorporation of hydrogen in the film is inevitable in most CVD process. It has been reported that the a-SiCN films with and without hydrogen incorporation prepared by CVD and IBSD (ion-beam sputtering deposition), respectively, exhibit similar compositions and bonding states of $\mathrm{C}, \mathrm{N}$, and $\mathrm{Si}$ [9]. Incorporation of hydrogen assists the formation of $\mathrm{C}-\mathrm{H}, \mathrm{N}-\mathrm{H}$ and $\mathrm{Si}-\mathrm{H}$ bonds in the films, resulting in the termination of dangling bonds of the a-SiCN network. The chemical composition and bonding states of the a-SiCN films were determined by a Perkin-Elmer Phi 1600 XPS system with a $(800-\mu \mathrm{m})^{2}$ sampling area and $11.75 \mathrm{eV}$ pass energy. $\mathrm{MgK}_{\alpha}$ radiation of $1253.6 \mathrm{eV}$ was used as the X-ray source, with a line width of $0.7 \mathrm{eV}$. The optical properties of refractive index ( $n$ and $k$ ) and transmittance and film thickness were determined by the spectral microreflectometry (Mission peaks optics, MP100-M), by measuring the interference between incident and reflected light with wavelengths ranging from UV to visible range (250-1000 $\mathrm{nm})$. All the samples for optical properties measurements were deposited on the quartz substrates. From the phase shift, the film thickness and refractive index ( $n$ and $k$ ) can be determined. The photovoltaic device with a MSM structure was fabricated by depositing the $800 \mathrm{~nm}$ thick a-SiCN film on the silicon substrate and evaporating the Au on top to form the electrode. Photocurrent measurements were completed using a $300 \mathrm{~W}$ Xenon lamp (Oriel) coupled to a monochromator as an illumination source and a Keithley 6487 source measurement unit to obtain the current and voltage.

\section{Result and discussion}

The composition of a-SiCN thin films deposited with different $\mathrm{CH}_{4}$ flow rates determined by XPS measurement is shown in Fig. 1. It is shown that the $\mathrm{C}$ content in the $\mathrm{SiCN}$

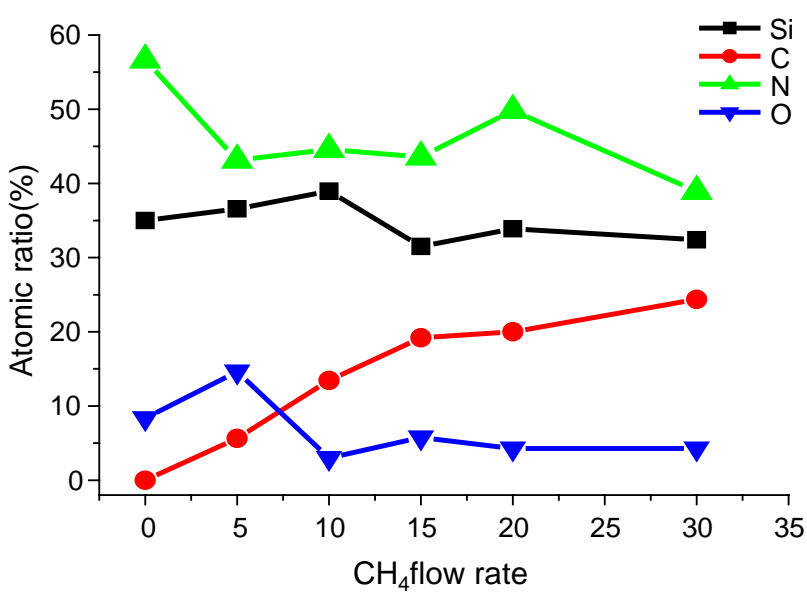

Fig. 1. The composition of a-SiCN thin films deposited with different $\mathrm{CH}_{4}$ flow rates determined by XPS measurement.

films gradually increases with the increasing $\mathrm{CH}_{4}$ flow rate up to $15 \mathrm{sccm}$ and reaches to a value around $25 \%$ for the 30 sccm $\mathrm{CH}_{4}$ flow rate. No significant variation of carbon content has been found in the a-SiCN thin films with further increasing the $\mathrm{CH}_{4}$ flow rate under current experimental conditions. Oxygen as impurity was found in all the deposited samples and the percentage of the oxygen content was kept below $5 \%$ for the films deposited with the $\mathrm{CH}_{4}$ flow rates higher than $10 \mathrm{sccm}$. Fig. 2 shows the transmission spectra of a-SiCN thin films with various carbon content. The film thicknesses for these films are 900(0 sccm $), 950(5 \mathrm{sccm}), 1040(10 \mathrm{sccm}), 1060(15 \mathrm{sccm})$, 1095(20 sccm), 1020(30 sccm) $\mathrm{nm}$, respectively. The average transmittance for these films in the visible light range is between $70 \%-90 \%$. In addition, the optical absorption band edge shifts toward the lower energy position as the carbon content increases. The dispersion of refractive index for a-SiCN thin films with various carbon content is shown in Fig. 3. The refractive index values $n(\lambda)$ of the a-SiCN thin films increase as the carbon content increases. The refractive index of the a-SiCN thin films varies from $\sim 2.0$ to $\sim 2.2$ while the carbon content changes from 0 to $25 \%$. These values are relatively closer to that of $\mathrm{Si}_{3} \mathrm{~N}_{4}(\sim 2.0)$ compared to that of $\mathrm{SiC}(\sim 2.6)$ due to the similarities of local bonding configurations between $\mathrm{SiCN}$ and $\mathrm{Si}_{3} \mathrm{~N}_{4}$ as mentioned above. The absorption coefficient $\alpha(\lambda)$ were deduced from the extinction coefficient $k(\lambda)$ measured by the spectral reflectometry and, subsequently, the optical band gap of the a-SiCN thin film $E_{\text {opt }}$, is obtained from the Tauc plot [10], $(\alpha h v)^{1 / 2}=B^{\text {Tauc }}\left(h v-E_{\text {opt }}\right)$ where $B^{\text {Tauc }}$ is a constant factor and $h v$ is the photon energy. Fig. 4 shows the variation of the optical band gap $\left(E_{\text {opt }}\right)$ obtained as a function of carbon content. It is clearly observed that the $E_{\text {opt }}$ values progressively decrease with increasing carbon content in the films. This result is consistent with the theoretical calculations [11], which indicates that the addition of $\mathrm{C}$ atoms in the $\alpha-\mathrm{Si}_{3} \mathrm{~N}_{4}$ network will lower the value of conduction band minimum (CBM) due to the high 


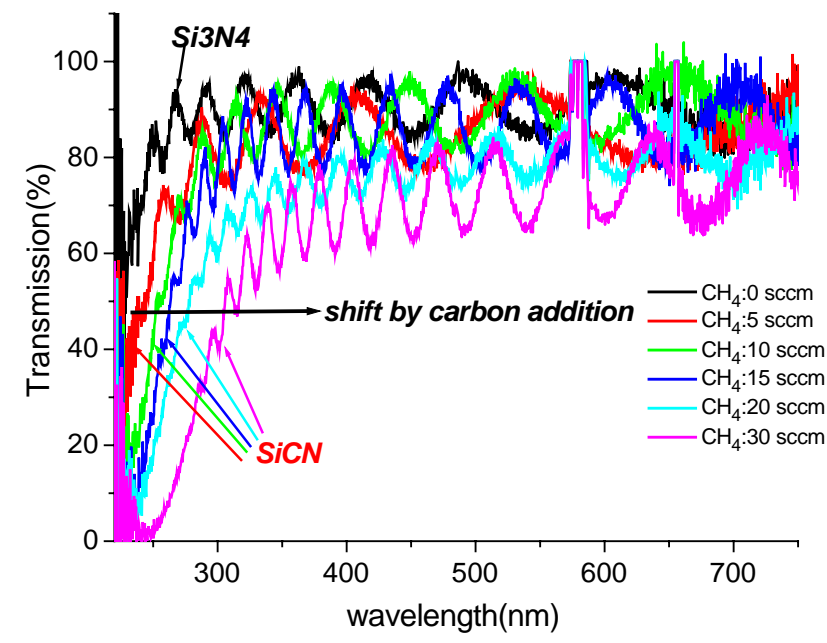

Fig. 2. The transmission spectra of a-SiCN thin films with various carbon content. The film thicknesses for these films are 900(0 sccm), $950(5 \mathrm{sccm})$, 1040(10 sccm), 1060(15 sccm), 1095(20 sccm), and 1020(30 sccm) nm, respectively.

localization of $\mathrm{C}$ compared to Si. From the above results, it is shown that optical properties of a-SiCN thin films can be tuned by varying the carbon content, providing the ability of band gap engineering.

Fig. 5(a) shows the characteristics of photocurrentvoltage response of the $\mathrm{Au} / \mathrm{a}-\mathrm{SiCN} / \mathrm{Si} \mathrm{MSM}$ photodetector device under the irradiation of light sources with various wavelengths. The composition of the a-SiCN thin film in the device is $\mathrm{Si}(35 \%): \mathrm{C}(24 \%): \mathrm{N}(39 \%): \mathrm{O}(2 \%)$ with a thickness of $800 \mathrm{~nm}$. It is clearly shown that the photoconductive current of the $\mathrm{Au} / \mathrm{a}-\mathrm{SiCN} / \mathrm{Si}$ device increases dramatically for the illuminating light with a wavelength shorter than 350 $\mathrm{nm}$, indicating that the device possesses a selective sensing feature of good solar-blind ability. The photocurrent $I_{\mathrm{p}}$ to dark current $I_{\mathrm{d}}$ ratio (PDCR) defined as $\frac{I_{\mathrm{p}}}{I_{\mathrm{d}}}$ reaches a value of 1800 for the incident light with a wavelength of $250 \mathrm{~nm}$ under an applied voltage of $5 \mathrm{~V}$, which is the highest value

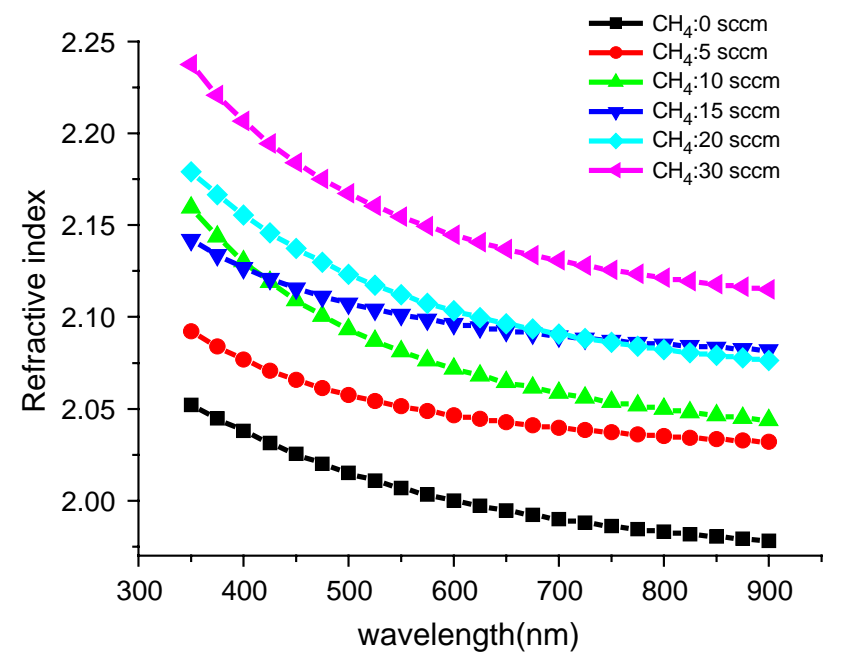

Fig. 3. The dispersion of refractive index of a-SiCN thin films with various carbon content.

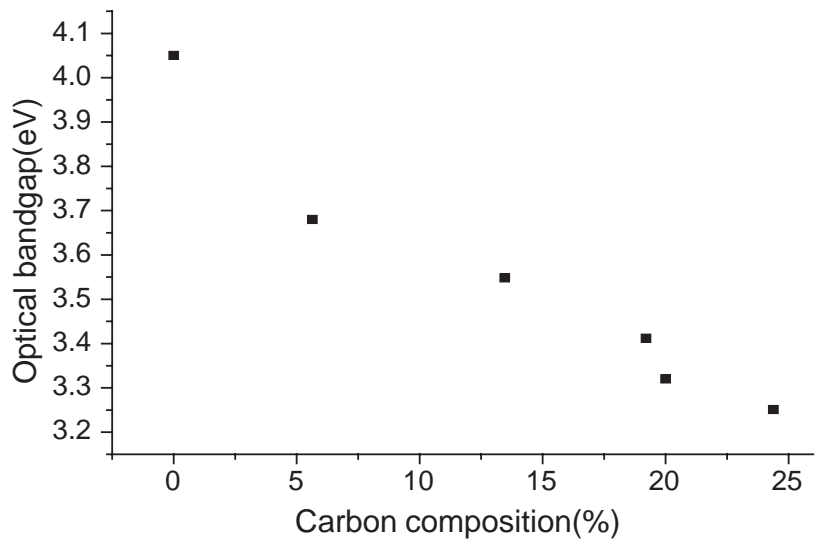

Fig. 4. Variations of the optical band gap $E_{\text {opt }}$ ( Tauc gap) of a-SiCN thin films with various carbon content.

so far reported for amorphous SiCN-based materials [12]. The small leakage current for the incident light with a wavelength longer than $350 \mathrm{~nm}$ is mainly due to the midgap states of the $\mathrm{SiCN}$ thin film in amorphous phase. For
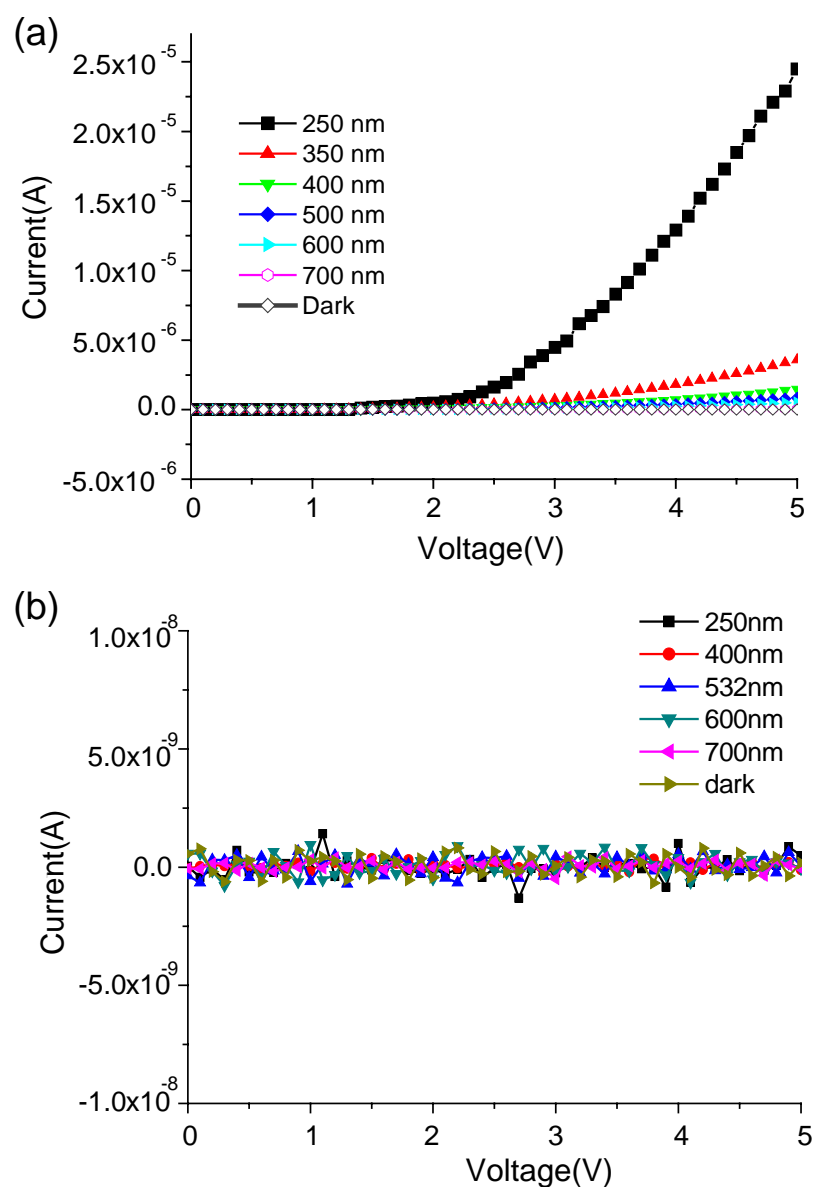

Fig. 5. (a) Characteristics of photocurrent-voltage response of the Au/a$\mathrm{SiCN} / \mathrm{Si} \mathrm{MSM}$ photodetector device under the irradiation of light sources with various wavelengths. The composition of the a-SiCN thin film in the device is $\mathrm{Si}(35 \%)$ : $\mathrm{C}(24 \%)$ : $\mathrm{N}(39 \%)$ : $\mathrm{O}(2 \%)$ with a thickness of $800 \mathrm{~nm}$. The photocurrent $I_{\mathrm{p}}$ to dark current $I_{\mathrm{d}}$ ratio (PDCR) is 1800 for the incident light with a wavelength of $250 \mathrm{~nm}$ under an applied voltage of $5 \mathrm{~V}$. (b) the $\mathrm{I}-\mathrm{V}$ characteristics of the $\mathrm{Au} / \mathrm{a}-\mathrm{Si} 3 \mathrm{~N} 4 / \mathrm{Si}$ device. 
comparison, the I-V characteristics of the $\mathrm{Au} / \mathrm{a}-\mathrm{Si} 3 \mathrm{~N} 4 / \mathrm{Si}$ device as shown in Fig.5(b) are measured under the same conditions as mentioned above. In contrast, there is no enhancement of current for the incident light with wavelength from 250 to $700 \mathrm{~nm}$, indicating the highly insulating properties of a- $\mathrm{Si}_{3} \mathrm{~N}_{4}$. The carbon content therefore plays an important role in determining the photoconductive response of the a-SiCN thin film. The reason for high photosensitivity of the a-SiCN thin film in the UV region is intriguing. It is believed that the significant enlargement of photoconductivity in the a-SiCN thin films may mainly result from the increase of absorption of light and from the enhancement of the conduction of photo-generated carriers as the carbon content increases. The increasing population of $\mathrm{sp}^{2}$-bonded $\mathrm{C}=\mathrm{N}$ or $\mathrm{C}=\mathrm{C}$ sites with increasing carbon content may also contribute to the increase of photoconductivity due to the delocalization of $\pi$ orbital characters. The detailed investigation of the transport mechanism depending on the carbon content in the a-SiCN thin film is on the way [13]. Combined with the excellent thermal stability and with the ability for band gap engineering by varying the carbon content, the a-SiCN based MSM device exhibiting high sensitivity to UV illumination can be further developed into the potential applications of UV photodetectors.

\section{Conclusion}

Optical properties of the a-SiCN thin films have been investigated as a function of carbon content. It was found that the refractive index $n$ increases as the carbon content increases. On the other hand, the transmittances and the optical band gaps of a-SiCN thin films progressively decrease with the increasing carbon content, providing the ability for band gap engineering. In addition, the simple $\mathrm{Au} /$
a-SiCN/Si MSM device demonstrates excellent selective UV sensing feature, which can be further developed into the potential applications of UV photodetectors.

\section{Acknowledgement}

This work is supported by National Science Council, Taiwan (Project No. NSC93-2120-M-002-010) and the US Airforce project (Project No. AFOSR-AOARD-04-4023).

\section{References}

[1] M. Dayan, J. Vac. Sci. Technol., A, Vac. Surf. Films 3 (1985) 361; E.C. Paloura, J. Lagowski, H.C. Gatos, J. Appl. Phys. 69 (1991) 3995.

[2] M.L. Cohen, Phys. Rev., B 32 (1985) 7988; A.Y. Liu, M.L. Cohen, Science 245 (1989) 841.

[3] L.C. Chen, C.Y. Yang, D.M. Bhusari, K.H. Chen, M.C. Lin, J.C. Lin, T.J. Chung, Diamond Relat. Mater. 5 (1996) 51.

[4] L.C. Chen, C.K. Chen, S.L. Wei, D.M. Bhusari, K.H. Chen, Y.F. Chen, Y.C. Jong, Y.S. Hunag, Appl. Phys. Lett. 72 (1998) 2463.

[5] A. Badzian, T. Badzian, Diamond Relat. Mater. 7 (1998) 1519.

[6] Y.K. Chang, H.H. Hsieh, W.F. Pong, M.H. Tsai, K.H. Lee, T.E. Dann, F.Z. Chien, P.K. Tseng, K.L. Tsang, W.K. Su, L.C. Chen, S.L. Wei, K.H. Chen, D.M. Bhusari, Y.F. Chen, Phys. Rev. 58 (1998) 9018.

[7] L.C. Chen, K.H. Chen, J.J. Wu, D.M. Bhusari, M.C. Lin, in: H.S. Nalwa (Ed.), Chapter 2 in Handbook of Si-Based Materials and Devices, Academic Press, 2001, p. 74, invited book chapter.

[8] S. Chattopadhyay, L.C. Chen, C.T. Wu, K.H. Chen, J.S. Wu, Y.F. Chen, G. Lehmann, P. Hess, Appl. Phys. Lett. 79 (2001) 332.

[9] H.C. Lo, J.J. Wu, C.Y. Wen, T.S. Wong, S.T. Lin, K.H. Chen, L.C. Chen, Diamond Relat. Mater. 10 (2001) 1916.

[10] J. Tauc, R. Grigorovici, A. Vancu, Phys. Status Solidi 15 (1996) 627.

[11] C.W. Chen, M.H. Lee, L.C. Chen, K.H. Chen, Diamond Relat. Mater. 13 (2004) 1158

[12] W.R. Chang, Y.K. Fang, S.F. Ting, Y.S. Tsair, C.N. Chang, C.Y. Lin, S.F. Chen, IEEE Electron Device Lett. 24 (2003) 565.

[13] C.W. Chen, unpublished work. 